\section{Radionuclide therapy}

Jamshed B Bomanji MBBS MSc PhD, Consultant and Honorary Senior Lecturer, Institute of Nuclear Medicine, University College London Hospitals NHS Trust, London

\section{Clin Med 2006;6:249-53}

Radionuclide therapy works by the principle of internal targeting. High tumour uptake is required for an effective radiation dose to be delivered to the target tissue. The efficacy of the radiopharmaceutical also depends on the residence time of the radionuclide in the tumour and the nature of the radiation (ie whether radionuclide decay is by beta-emission, alpha-emission, electron capture or internal conversion). Table 1 lists the radiopharmaceuticals commonly used for therapy.

Prior to most radionuclide therapy procedures a diagnostic scan is performed to assess the extent of metastases and their avidity for the therapeutic agent. Decision to treat is usually multidisciplinary. Full written information is given to the patient and written informed consent obtained for all radionuclide therapies. The medical internal radiation dose schema is the accepted method for calculating radiation dose from internally administered radiopharmaceuticals.

\section{Thyrotoxicosis}

Radioiodine (I-131) has been used for the treatment of thyrotoxicosis for several decades (Fig 1). ${ }^{1}$ The physiological basis for the use of I-131 therapy in thyrotoxicosis is that non-radioactive iodine is an essential component of thyroid hormone and is actively taken up by thyroid follicles. The main indication for I-131 therapy is failure of medical antithyroid drug therapy or recurrence of thyrotoxicosis afterwards. Patients with allergic reactions to antithyroid medications are also candidates for therapy. ${ }^{2,3}$

Most patients may receive I-131 while being symptomatically treated with just a beta-blocker, which is then reduced as the thyrotoxic state resolves. ${ }^{2}$ Patients with coronary disease, the elderly and those with severe hyperthyroidism are rendered euthyroid with medical treatment which is stopped four days prior to I-131 therapy. All iodine-containing medications should be avoided (eg amiodarone, contrast agents) prior to therapy.

One treatment dose of I-131 is usually sufficient and is effective in 3-4 weeks. Thyroid function tests should be performed 4-8 weeks later. ${ }^{3}$ The free thyroxine $\left(\mathrm{FT}_{4}\right)$ levels may fall within 6-8 weeks but then rise again (due to release of stored thyroid hormones from injured thyroid cells), usually followed by a fall to hypothyroid levels. ${ }^{1,4}$ Relapse occurs months later in a small percentage of patients and a second dose of radioiodine is recommended for them. Follow-up is with monitoring of thyroid function at around 8-12 weeks.

\section{Contraindications}

Pregnancy and breast feeding are contraindications to I-131 therapy. ${ }^{2}$ I-131 should be given with caution under steroid cover $(0.4-0.5 \mathrm{mg} / \mathrm{kg} /$ day for 1 month, tapered over the following month) in patients with Graves' ophthalmopathy as this may worsen in about $15 \%$ of cases. Smoking increases the risk of flare in ophthalmopathy following I-131 therapy. ${ }^{5}$ The main consequence of radioiodine therapy is post-therapy hypothyroidism, occurring in $80-90 \%$ of patients within the first year. ${ }^{6}$ However, such long-term hypothyroidism is easily managed with $\mathrm{T}_{4}$ supplementation, with no known long-term complications.

\section{Follow-up}

Follow-up intervals of 6-12 months are recommended. ${ }^{3}$ There appears to be no risk of subsequent leukaemia, thyroid cancer or other malignancies. ${ }^{1,2,4}$ Children born to parents previously treated with I-131 show normal rates of congenital abnormalities.

\section{Thyroid cancer}

Approximately 900 new cases of thyroid cancer are recorded in England and Wales each year. ${ }^{7}$ Overall 10-year survival rate for differentiated thyroid cancer is $80-90 \%{ }^{7,8}$ Local or regional recurrences develop in $5-20 \%$ and distant metastases in $10-15 \%$. I-131 has been used in the treatment of patients with differentiated thyroid cancers over the past four decades and its use is well established. Mortality rates in patients who have not received I-131 ablation are two and three times higher than in those who have received this therapy by 10 years and 25 years, respectively. ${ }^{9}$

I-131 has two main therapeutic indications:

- ablation of residual normal thyroid tissue following surgery

- treatment of recurrent disease.

\section{Key Points}

Prior to all radionuclide therapy procedures a diagnostic scan is performed and written informed consent is requested from patient

Radioactive iodine (I-131) is an excellent method of treating overactive thyroid tissue (either diffuse or toxic nodular goitre)

In majority of patients with differentiated thyroid cancer (tumour size of $1 \mathrm{~cm}$ or more), I-131 is the treatment of choice after total thyroidectomy

Bone pain from osteoblastic bone metastases can be ameliorated $45-90 \%$ of the time using strontium-89 $\left({ }^{89} \mathrm{Sr}\right)$ and samarium-153 ( $\left.{ }^{153} \mathrm{SM}\right)$

B-cell NHL have proven most responsive to radiolabelled monoclonal antibody theray because they are particularly susceptible to radiation induced apoptosis

KEY WORDS: lymphomas, neuroendocrine tumours, radionuclide therapy, thyroid cancer, thyrotoxicosis 
Table 1. Radiopharmaceuticals commonly used for therapy.

\begin{tabular}{|c|c|c|c|c|}
\hline \multicolumn{2}{|c|}{ Radiopharmaceuticals Clinical indications } & \multirow{2}{*}{$\begin{array}{l}\text { Dose } \\
\text { 400-800 MBq (orally) }\end{array}$} & \multirow{2}{*}{$\begin{array}{l}\text { Acute toxicity } \\
\text { Transient worsening of } \\
\text { ophthalmopathy, radiation } \\
\text { thyroiditis, thyrotoxic crisis }\end{array}$} & \multirow{2}{*}{$\begin{array}{l}\text { Delayed toxicity } \\
\text { Transient or permanent } \\
\text { hypothyroidism or } \\
\text { hypoparathyroidism }\end{array}$} \\
\hline |-131-sodium iodide & Thyrotoxicosis & & & \\
\hline & Differentiated thyroid cancer & & Neck discomfort with & Low incidence of \\
\hline & Post-surgery ablation & 3.7 GBq (orally) & sialoadenitis, taste & cancers $(0.5 \%)$ \\
\hline & & & abnormalities, radiation & Radiation fibrosis can \\
\hline & Treatment of recurrence & $\begin{array}{l}3.7-5.5 \mathrm{GBq} \text { (orally) } \\
\text { in shielded room }\end{array}$ & $\begin{array}{l}\text { cystitis, radiation gastritis - } \\
\text { all extremely rare }\end{array}$ & $\begin{array}{l}\text { occur in patients with } \\
\text { diffuse pulmonary } \\
\text { metastases }\end{array}$ \\
\hline${ }^{89} \mathrm{Sr}$-chloride & Bone pain palliation & $\begin{array}{l}148 \mathrm{MBq} \text { slow iv injection } \\
\text { (1-2 min), accompanied } \\
\text { by iv or oral hydration } \\
(\geq 500 \mathrm{ml})\end{array}$ & None & $\begin{array}{l}\text { Haematopoietic } \\
\text { suppression }\end{array}$ \\
\hline${ }^{153} \mathrm{Sm}$-EDTMP & Bone pain palliation & $\begin{array}{l}37 \mathrm{MBq} / \mathrm{kg} \text { slow iv } \\
\text { injection (1-2 } \mathrm{min}) \text {, }\end{array}$ & None & $\begin{array}{l}\text { Haematopoietic } \\
\text { suppression }\end{array}$ \\
\hline
\end{tabular}

${ }^{90}$ Y-ibritumomab B cell non-Hodgkin's tiuxetan (Zevalin) anti-CD22 antibody lymphoma not responding to conventional therapy 1-131-tositumomab (Bexxar) anti-CD20 antibody
Non-Hodgkin's lymphoma not responding to rituximab and chemotherapy

$\begin{array}{ll}\begin{array}{l}\text { I-131-meta- } \\ \text { iodobenzylguanidine } \\ \text { (MIBG) }\end{array} & \begin{array}{l}\text { Metastatic neuroendocrine } \\ \text { tumours } \\ \text { (phaeochromocytomas, } \\ \text { paragangliomas, carcinoids) } \\ \text { and neuroblastomas }\end{array} \\ \begin{array}{l}\text { 90Y-(DOTA-Tyr }{ }^{3} \text { )- } \\ \text { octreotide }\end{array} & \begin{array}{l}\text { Metastatic neuroendocrine } \\ \text { tumours }\end{array}\end{array}$

${ }^{177}$ Lu-TATE (DOTA ${ }^{\circ}$ -Tyr ${ }^{3}$ )-octreotate
Metastatic neuroendocrine tumours accompanied by iv or oral hydration ( $\geq 500 \mathrm{ml}$ )

Infusion of $250 \mathrm{mg} / \mathrm{m}^{2}$ rituximab (not included in the kit) preceding a fixed dose of $185 \mathrm{MBq}$ of diagnostic indium-111 $\left({ }^{111} \mathrm{I}\right)$

Zevalin administered as a slow iv infusion (over $10 \mathrm{~min}$ ).

7-9 days later, a second infusion of $250 \mathrm{mg} / \mathrm{m}^{2}$ rituximab is given followed by $14.8 \mathrm{MBq} / \mathrm{kg}$ of ${ }^{90}$ Y-Zevalin ( $\left.\geq 1.18 \mathrm{GBq}\right)$ slow iv infusion

l-131-tositumomab must be given with tositumomab ( $\mathrm{T}$ ). Dosimetry step: $450 \mathrm{mg} \mathrm{T}$ over $60 \mathrm{~min}$ followed by l-131-tositumomab containing $35 \mathrm{mg} \mathrm{T}$ with 185 MBq l-131 Therapy step: calculated to deliver 75 cGy total body irradiation with $35 \mathrm{mgT}$, iv over $20 \mathrm{~min}$

\section{7-11.1 GBq iv infusion over 30-45 $\mathrm{min}$ in shielded room Monitor vital signs during and post-infusion}

\section{7-5.5 GBq of ${ }^{90}$ Y-labelled Nausea, vomiting, SMS analogues abdominal pain} iv co-infusion of amino acid (arginine and lysine) using Hartmann-HEPA 8\%) for renal protection
3.7-7.4 GBq ${ }^{177} \mathrm{Lu}$-labelled SMS analogues

Nausea, vomiting abdominal pain
Rituximab infusion reaction symptom complex (asthenia, chills, fever, nausea)

Hypersensitivity reactions (asthenia, chills, fever, nausea)

Nausea, vomiting
Prolonged and severe myelosuppression, nausea, vomiting, abdominal pain, arthralgia
Prolonged severe myelosuppression, nausea, vomiting, abdominal pain, arthralgias I-131-tositumomab may be less myelotoxic than ${ }^{90}$ Y-ibritumomab tiuxetan

Myelosuppression uncommon and only after multiple doses

Renal insufficiency and haematological and liver toxicity rare

EDTMP = ethylenediamine-tetra-methylenephosphoric acid; iv = intravenous; SMS = somatostatin

Renal, haematological and liver toxicity rare 


\section{Thyroid ablation}

Following surgery for a thyroid nodule and histological confirmation of malignancy $(\geq 1.5 \mathrm{~cm}$ in diameter) ablation of residual thyroid tissue is now an accepted part of management guidelines. ${ }^{9}$ Ablation destroys a potential site of malignant recurrence, ensures subsequent uptake of therapeutic I-131 into recurrent tumour sites and facilitates interpretation of diagnostic I-131 scan and thyroid binding globulin ( $\mathrm{TBg}$ ) levels. TBg is usually measured three months after therapy.

I-131 therapy is most useful in patients with follicular thyroid cancer and papillary tumours with follicular elements but ablation is also undertaken in patients with pure papillary tumours or medullary thyroid cancers. ${ }^{10,11}$ Most centres use a fixed high or low dose for thyroid ablation (Table 1), given on an inpatient basis in a special lead-lined room.

\section{Treatment of recurrent disease}

Any I-131 tracer uptake not due to normal biodistribution after thyroid remnant ablation can be attributed to tumour recurrence. This can be successfully treated with large doses of I-131 (Table 1; Fig 2). Local recurrence and distant metastases, including those to the lung, respond well to therapy. Bone metastases,

Fig 1. Patient with thyrotoxicosis given $600 \mathrm{MBq}$ of $\mathrm{I}-131$ to treat a functioning

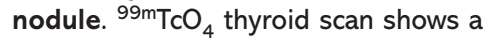
functioning nodule in the lower pole of the left thyroid lobe, with suppression of the remainder of the gland. The thyroid uptake is high, at $12.5 \%$ (normal range $1-3 \%$ ).

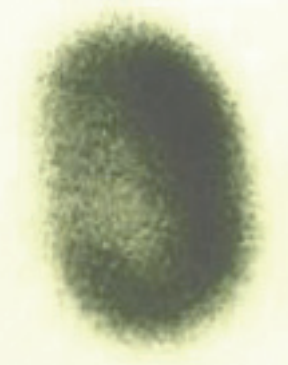

however, appear more resistant to treatment. Brain metastases are best treated surgically since I-131 is ineffective.

Ablation requires thyroid stimulating hormone (TSH) levels above $30 \mathrm{mIU} / \mathrm{l}$ to ensure optimum uptake of I-131 into thyroid cancer cells. This can be achieved by withdrawal of $\mathrm{T}_{4}$ for approximately four weeks, triiodothyronine for 12 days or by giving an intramuscular injection of recombinant human TSH two days before the therapy dose.

Pregnant women may not receive I-131. Women are advised to avoid pregnancy for at least four months and men with abnormal spermatozoa for six months following I-131 therapy. ${ }^{11}$ Sperm banking is advised in young men. ${ }^{9}$

\section{Bone pain palliation}

Strontium-89 ( $\left.{ }^{89} \mathrm{Sr}\right)$ and samarium-153 $\left({ }^{153} \mathrm{Sm}\right)$ are radionuclides approved in the USA and Europe for palliation of pain from bone metastases, especially in patients with prostate and breast cancer. ${ }^{12,13}$ The recommended doses for ${ }^{89} \mathrm{Sr}$ and ${ }^{153} \mathrm{Sm}$ are shown in Table1. The selection of patients should take into consideration:

- marrow function

- performance status

- recent use of other marrow suppression agents (chemotherapy or radiotherapy)

- unsuitability for alternate palliative interventions (wide-field or local-field radiotherapy, hormone therapy, chemotherapy, bisphosphonates), and

- anticipated life expectancy.

\section{Pain relief}

Response rates in terms of pain relief vary from $40-95 \% .{ }^{14,15}$ Pain relief starts 1-4 weeks after treatment, continues for up to 18 months and is associated with reduction in analgesic use in many patients. Thrombocytopenia and neutropenia are the most common toxic
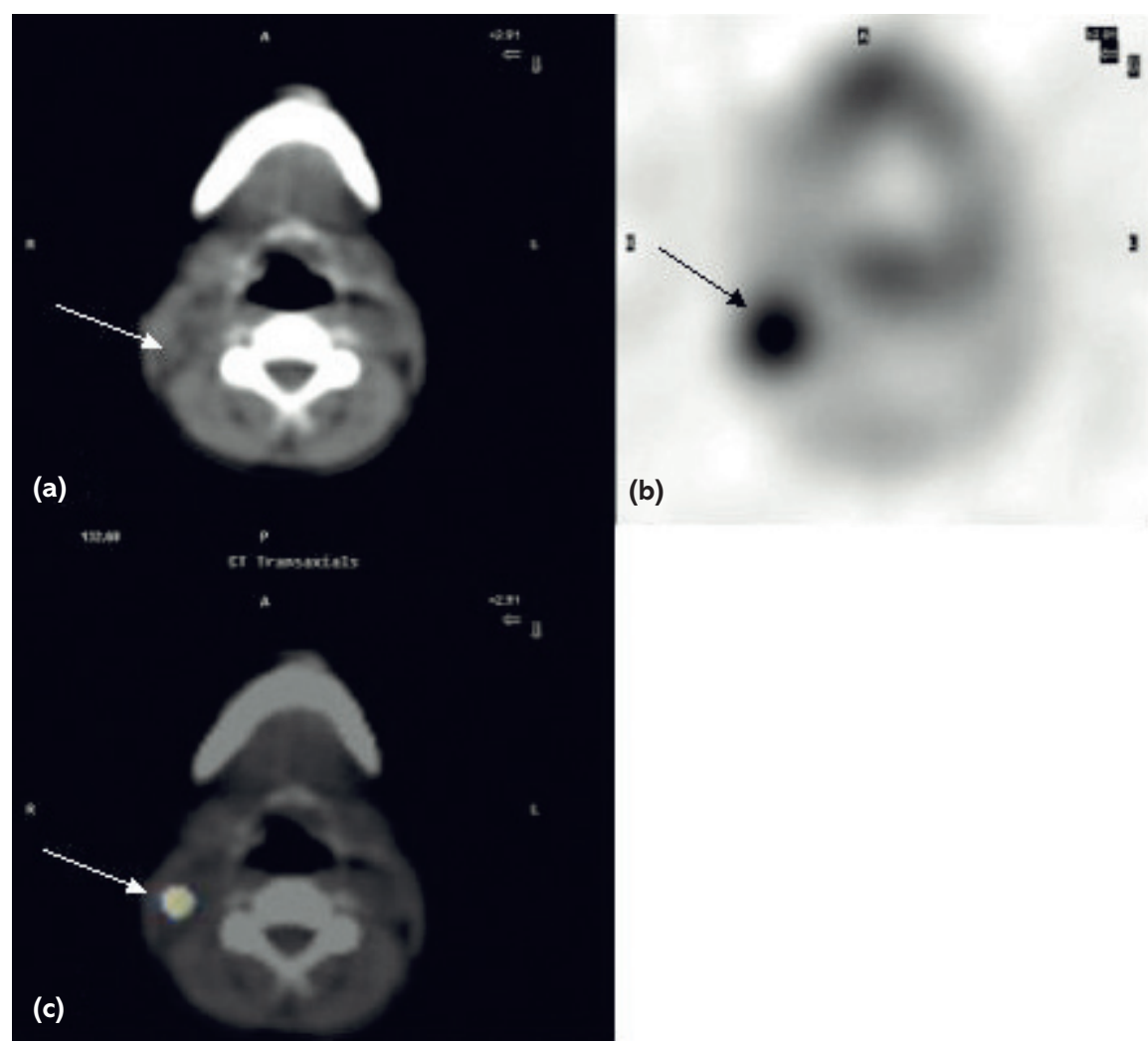

(b)

Fig 2. Patient with recurrent follicular thyroid cancer treated with $5.5 \mathrm{GBq}$ I-131:

(a) computed tomography (CT) shows an enlarged right cervical lymph node (arrow);

(b) I-131 post-therapy single-photon emission tomography (SPET) shows avid uptake of the therapeutic dose in the right cervical node; (c) CT and SPET fused image. 
effects (30-50\% of patients). ${ }^{14}$ The maximum nadir of platelet and leucocyte counts occurs $2-5$ weeks after treatment and is usually reversible within 12 weeks. Repeat doses are effective in providing pain relief in many patients. The effectiveness of radionuclides can be greater when combined with chemotherapeutic agents such as cisplatin. ${ }^{16}$ Some studies with ${ }^{89} \mathrm{Sr}$ and ${ }^{153} \mathrm{Sm}$ indicate a reduction of osteoblastic lesions on bone scans in up to $70 \%$ of patients, suggesting a possible tumoricidal action. ${ }^{15}$

\section{Radiolabelled monoclonal antibody therapy}

Clinical indications have recently been approved for radiolabelled monoclonal antibody (MAb) therapy (Table 1): ${ }^{17-19}$

- In 2002, the Food and Drug Administration (FDA) approved yttrium-90 $\left({ }^{90} \mathrm{Y}\right)$-labelled ibritumomab tiuxetan (Zevalin) which delivers radioactivity directly to cancerous B lymphocytes.

- I-131-tositumomab (Bexxar) was approved by the FDA in 2003 but awaits approval in Europe.

\section{$90 Y$-ibritumomab tiuxetan (Zevalin)}

${ }^{90} \mathrm{Y}$-ibritumomab is a murine immunoglobulin (Ig) G1 anti-CD20 MAb, attached via a linker tiuxetan to ${ }^{90} \mathrm{Y}$ to form ${ }^{90}$ Y-ibritumomab. Ibritumomab is directed against the CD20 antigen expressed on the surface of most normal and malignant B lymphocytes. ${ }^{17}$

Therapy is given in a two-step procedure:

1 A single infusion of $250 \mathrm{mg} / \mathrm{m}^{2}$ rituximab (not included in the Zevalin kits) preceding a fixed dose of $185 \mathrm{MBq}$ (1.6 mg total antibody dose) of diagnostic indium-111

${ }^{111}$ In) Zevalin administered as a slow intravenous (iv) infusion (over $10 \mathrm{~min})$.

2 After 7-9 days, a second infusion of $250 \mathrm{mg} / \mathrm{m}^{2}$ of rituximab prior to 14.8 MBq/kg of ${ }^{90} \mathrm{Y}-$ Zevalin administered as a slow iv infusion (over $10 \mathrm{~min}$ ).
A recent randomised, controlled phase III trial reported an overall response rate of $80 \%$, with complete response in $30 \% .{ }^{20}$ More than $5 \%$ of subjects experienced adverse events, including nausea, vomiting, diarrhoea, anorexia, thrombocytopenia, neutropenia, anaemia, arthralgia, dizziness, dyspnoea and increased cough.

\section{I-131-tositumomab (Bexxar)}

I-131-tositumomab is a murine IgG2a anti-CD20 MAb. Indications include CD20 antigen-expressing relapsed or refractory, low-grade, follicular or transformed non-Hodgkin's lymphoma, including cases of rituximab-refractory non-Hodgkin's lymphoma. It is administered as a single course of treatment (the safety of multiple courses or combinations with other forms of radiation or chemotherapy has not been evaluated).

The therapeutic regimen consists of four components administered in two discrete steps: the dosimetric step, followed 7-14 days later by a therapeutic step (doses listed in Table 1). The overall response rate in a pivotal trial was $65 \%$, with complete response in $20 \% .^{21}$

\section{Contraindications to radiolabelled monoclonal antibody therapy}

In general, radiolabelled MAbs are contraindicated in the presence of compromised blood counts, impaired renal function, more than $25 \%$ bone marrow involvement, obvious myelodysplasia and a history of human anti-mouse antibodies. ${ }^{17,19}$

\section{Neuroendocrine tumours}

Radiolabelled meta-iodobenzylguanidine (mIBG) and somatostatin (SMS) analogues are frequently used to treat neuroendocrine tumours. ${ }^{8}$

\section{I-131-meta-iodobenzylguanidine}

mIBG is a guanethidine analogue selectively concentrated by phaeochromocytoma, paragangliomas, carcinoids and medullary carcinoma of the thyroid (Fig 3). Neuroblastomas also show high uptake. Most literature and guidelines recommend I-131-mIBG doses of 3.7-11.1 GBq for these tumours. ${ }^{22-25}$ Several doses may be required (usually at intervals of 12-16 weeks) to obtain an objective response. Symptomatic improvement is observed in $76 \%$ of patients with metastatic phaeochromocytoma and paraganglioma, with tumour responses in 30-50\% and hormonal responses in $45 \% .{ }^{23}$ Symptomatic response in patients with metastatic carcinoid tumours is noted in $49 \%$, hormonal response in $53 \%$ and radiographic tumour response in $76.5 \%{ }^{26}$

Side effects are minimal. Nausea and vomiting may occur during the first two days post-therapy and there may be transient myelosuppression 4-6 weeks post-therapy. Bone marrow suppression is more likely in patients who have bone marrow involvement at the time of I-131-mIBG therapy.

\section{Radiolabelled somatostatin analogue therapy}

Radiolabelled ${ }^{111} \mathrm{In},{ }^{90} \mathrm{Y}$ and lutetium-177 $\left({ }^{177} \mathrm{Lu}\right)$ SMS analogues have been used mainly for gastroenteropancreatic tumours. Several doses may be required

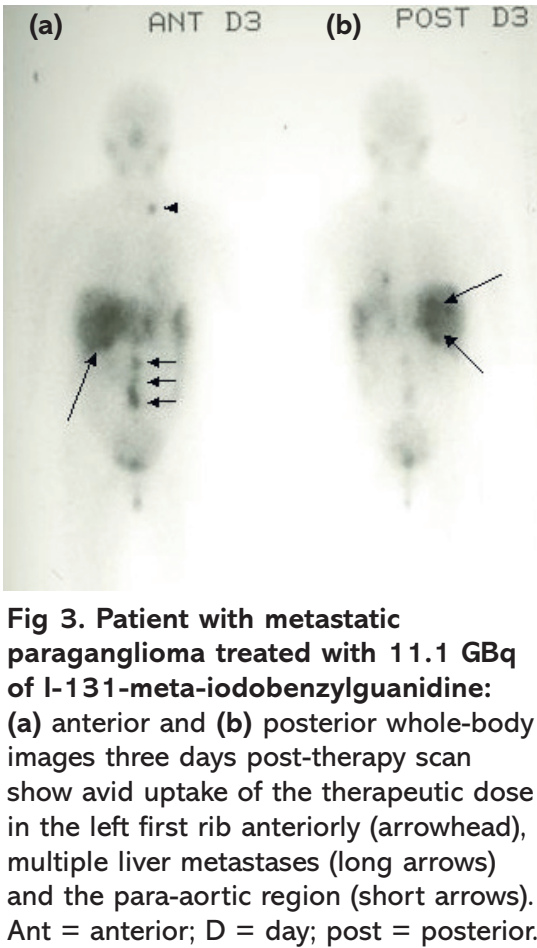


to obtain an objective response; the treatment should not be repeated at intervals of less than 4-6 weeks.

Improvement in clinical symptoms has been observed in more than $60 \%$ of patients after treatment, with objective response in 23\% (World Health Organization criteria), complete response in 3-6\%, partial response in about $22 \%$, stable disease in about $58 \%$ and progression in $15 \% .^{27-30}$ These promising tumour responses are essentially similar in most ${ }^{90} \mathrm{Y}-$ and ${ }^{177} \mathrm{Lu}$-labelled SMS analogue studies, despite differences in therapy regimens.

Side effects include nausea and vomiting, which may occur within 24 hours after administration. ${ }^{29}$ Radiolabelled octreotide is significantly retained in the proximal tubules and therefore the radiation dose to the kidneys is a dose-limiting factor. Renal function loss and even end-stage renal disease have been reported after therapy with ${ }^{30}$ Y-DOTATOC. ${ }^{31}$ Patients can develop grade II-III haematological toxicity. Thrombocytopenia and liver toxicity have also been reported in some patients. In the long term, a small number of patients develop myelodysplastic syndrome and leukopenia. ${ }^{30}$

\section{References}

1 Cooper D. Treatment of thyrotoxicosis. In: Braverman LE, Utiger RD (eds). Werner and Ingbar's the thyroid. Philadelphia: Lippincott Williams \& Wilkins, 2000:697.

2 Lazarus JH. Guidelines for the use of radioiodine in the management of hyperthyroidism: a summary. Prepared by the Radioiodine Audit Subcommittee of the Royal College of Physicians Committee on Diabetes and Endocrinology, and the Research Unit of the Royal College of Physicians. $J R$ Coll Physicians Lond 1995;29:464-9.

3 Vanderpump MP, Ahlquist JA, Franklyn JA, Clayton RN. Consensus statement for good practice and audit measures in the management of hypothyroidism and hyperthyroidism. The Research Unit of the Royal College of Physicians of London, the Endocrinology and Diabetes Committee of the Royal College of Physicians of London, and the Society for Endocrinology. Review. BMJ 1996;313:539-44.

4 Weetman AP. Graves' disease. Review. N Engl J Med 2000;343:1236-48.

5 Bartalena L, Marcocci C, Tanda ML et al. Cigarette smoking and treatment outcomes in Graves' ophthalmopathy. Ann Intern Med 1998;129:632-5.

6 Cunnien AJ, Hay ID, Gorman CA, Offord KP, Scanlon PW. Radioiodine-induced hypothyroidism in Graves' disease: factors associated. J Nucl Med 1982;23:978-83.

7 Coleman PM, Babb P, Damiecki P et al. Cancer survival trends in England and Wales 1971-1995: deprivation and NHS region. London: Stationery Office, 1999:471-8.

8 Hundahl SA, Fleming ID, Fremgen AM, Menck HR. A National Cancer Data Base report on 53,856 cases of thyroid carcinoma treated in the U.S., 1985-1995. Cancer 1998;83:2638-48.

9 Guidelines for the management of thyroid cancer in adults. London: Royal College of Physicians of London and British Thyroid Association, 2002.

10 Sherman SI. Thyroid carcinoma. Review. Lancet 2003;361:501-11.

11 Kinder BK. Well differentiated thyroid cancer. Review. Curr Opin Oncol 2003;15: $71-7$

12 Therapeutic Radiopharmaceutical Guidelines Group. Radiopharmaceuticals for the palliation of painful bone metastases (full report). Practice guideline report; no. 14-1. Toronto, ON: Cancer Care Ontario (CCO), 2004.

13 Liepe K, Runge R, Kotzerke J. Systemic radionuclide therapy in pain palliation. $\mathrm{Am}$ J Hosp Palliat Care 2005;22:457-64.

14 Bauman G, Charette M, Reid R, Sathya J. Radiopharmaceuticals for the palliation of painful bone metastasis - a systemic review. Radiother Oncol 2005;75:258-70.

15 Finlay IG, Mason MD, Shelley M. Radioisotopes for the palliation of metastatic bone cancer: a systematic review. Lancet Oncol 2005;6:392-400.

16 Tu SM, Kim J, Pagliaro LC et al. Therapy tolerance in selected patients with androgen-independent prostate cancer following strontium-89 combined with chemotherapy. J Clin Oncol 2005;23: 7904-10.

17 Silverman DH, Delpassand ES, Torabi F et al. Radiolabeled antibody therapy in non-Hodgkins lymphoma: radiation protection, isotope comparisons and quality of life issues. Review. Cancer Treat Rev 2004; 30:165-72.

18 Leonard JP, Furman RR, Ruan J, Coleman M. New developments in immunotherapy for non-Hodgkin's lymphoma. Review. Curr Oncol Rep 2005;7:364-71.

19 Lemieux B, Coiffier B. Radio-immunotherapy in low-grade non-Hodgkin's lymphoma. Review. Best Pract Res Clin Haematol 2005;18:81-95.

20 Witzig TE, Gordon LI, Cabanillas F et al. Randomized controlled trial of yttrium-90-labeled ibritumomab tiuxetan radioimmunotherapy versus rituximab immunotherapy for patients with relapsed or refractory low-grade, follicular, or transformed B-cell non-Hodgkin's lymphoma. J Clin Oncol 2002;20:2453-63.

21 Kaminski MS, Zelenetz AD, Press OW et al. Pivotal study of iodine I 131 tositumomab for chemotherapy-refractory low-grade or transformed low-grade B-cell nonHodgkin's lymphomas. J Clin Oncol 2001 19:3918-28.

22 Guidelines for ${ }^{131}$ I-meta iodo benzylguanidine therapy. EANM Radionuclide Therapy Committee guidelines, 2002. www.eanm. org/scientific_info/guidelines/guidelines

23 Loh KC, Fitzgerald PA, Matthay KK, Yeo PP, Price DC. The treatment of malignant pheochromocytoma with iodine-131 metaiodobenzylguanidine (131I-MIBG): a comprehensive review of 116 reported patients. J Endocrinol Invest 1997;20:648-58.

24 Mukherjee JJ, Kaltsas GA, Islam N et al. Treatment of metastatic carcinoid tumours, phaeochromocytoma, paraganglioma and medullary carcinoma of the thyroid with (131)I-metaiodobenzylguanidine ((131)ImIBG). Clin Endocrinol (Oxf) 2001;55: 47-60.

25 Bomanji JB, Wong W, Gaze MN et al. Treatment of neuroendocrine tumours in adults with 131I-MIBG therapy. Review. Clin Oncol (R Coll Radiol) 2003;15:193-8.

26 Safford SD, Coleman RE, Gockerman JP et al. Iodine-131 metaiodobenzylguanidine treatment for metastatic carcinoid. Results in 98 patients. Cancer 2004;101:1987-93.

27 De Jong M, Breeman WA, Bernard HF et al. Therapy of neuroendocrine tumors with radiolabeled somatostatin-analogues. Q J Nucl Med 1999;43:356-66.

28 Weiner RE, Thakur ML. Radiolabeled peptides in diagnosis and therapy. Review. Semin Nucl Med 2001;31:296-311.

29 Teunissen JJ, Kwekkeboom DJ, de Jong M et al. Endocrine tumours of the gastrointestinal tract. Peptide receptor radionuclide therapy. Review. Best Pract Res Clin Gastroenterol 2005;19:595-616.

30 Kwekkeboom DJ, Teunissen JJ, Bakker WH et al. Radiolabeled somatostatin analog [177Lu-DOTA0,Tyr3] octreotate in patients with endocrine gastroenteropancreatic tumors. J Clin Oncol 2005;23:2754-62.

31 Valkema R, Pauwels SA, Kvols LK et al. Long-term follow-up of renal function after peptide receptor radiation therapy with (90)Y-DOTA $(0), \operatorname{Tyr}(3)$-octreotide and (177)Lu-DOTA(0), Tyr(3)-octreotate. J Nucl Med 2005;46(Suppl 1):83S-91S. 